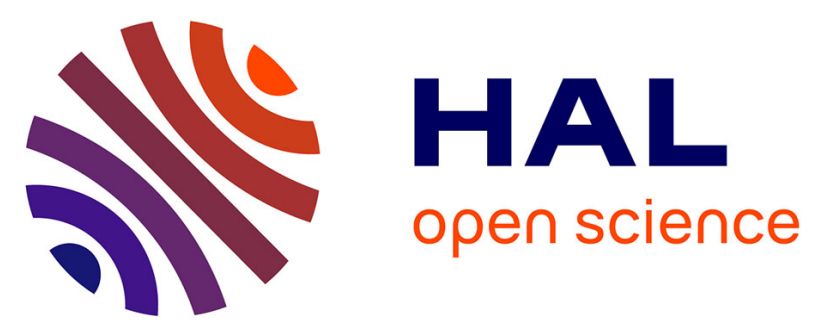

\title{
First simultaneous global measurements of nighttime stratospheric NO2 and NO3 observed by Global Ozone Monitoring by Occultation of Stars (GOMOS)/Envisat in 2003
}

\author{
Alain Hauchecorne, Jean-Loup Bertaux, Francis Dalaudier, Charles Cot, \\ Jean-Claude Lebrun, Slimane Bekki, Marion Marchand, E. Kyrölä, J. \\ Tamminen, Viktoria Sofieva, et al.
}

\section{- To cite this version:}

Alain Hauchecorne, Jean-Loup Bertaux, Francis Dalaudier, Charles Cot, Jean-Claude Lebrun, et al. First simultaneous global measurements of nighttime stratospheric NO2 and NO3 observed by Global Ozone Monitoring by Occultation of Stars (GOMOS)/Envisat in 2003. Journal of Geophysical Research: Atmospheres, 2005, 110, pp.D18301. 10.1029/2004JD005711 . hal-00069491

\author{
HAL Id: hal-00069491 \\ https://hal.science/hal-00069491
}

Submitted on 25 Mar 2015

HAL is a multi-disciplinary open access archive for the deposit and dissemination of scientific research documents, whether they are published or not. The documents may come from teaching and research institutions in France or abroad, or from public or private research centers.
L'archive ouverte pluridisciplinaire HAL, est destinée au dépôt et à la diffusion de documents scientifiques de niveau recherche, publiés ou non, émanant des établissements d'enseignement et de recherche français ou étrangers, des laboratoires publics ou privés. 


\title{
First simultaneous global measurements of nighttime stratospheric $\mathrm{NO}_{2}$ and $\mathrm{NO}_{3}$ observed by Global Ozone Monitoring by Occultation of Stars (GOMOS)/Envisat in 2003
}

\author{
A. Hauchecorne, ${ }^{1}$ J.-L. Bertaux, ${ }^{1}$ F. Dalaudier, ${ }^{1}$ C. Cot,${ }^{1}$ J.-C. Lebrun, ${ }^{1}$ S. Bekki, ${ }^{1}$ \\ M. Marchand, ${ }^{1}$ E. Kyrölä, ${ }^{2}$ J. Tamminen, ${ }^{2}$ V. Sofieva, ${ }^{2}$ D. Fussen, ${ }^{3}$ F. Vanhellemont, ${ }^{3}$ \\ O. Fanton d'Andon, ${ }^{4}$ G. Barrot,${ }^{4}$ A. Mangin, ${ }^{4}$ B. Théodore, ${ }^{4}$ M. Guirlet, ${ }^{4}$ P. Snoeij, ${ }^{5}$ \\ R. Koopman, ${ }^{6}$ L. Saavedra de Miguel, ${ }^{6}$ R. Fraisse, ${ }^{7}$ and J.-B. Renard ${ }^{8}$ \\ Received 17 December 2004; revised 13 May 2005; accepted 11 July 2005; published 20 September 2005.
}

[1] The Global Ozone Monitoring by Occultation of Stars (GOMOS) stellar occultation instrument on board the Envisat European satellite provides global coverage of ozone and other stratospheric species with good vertical resolution and a self-calibrating method. In this paper we present the first simultaneous global distribution of stratospheric $\mathrm{NO}_{2}$ and $\mathrm{NO}_{3}$ from 1 year of nighttime GOMOS data in 2003. Most previous $\mathrm{NO}_{2}$ satellite observations have been made using the solar occultation technique. They are difficult to interpret due to the fast photochemical evolution of $\mathrm{NO}_{2}$ at sunrise and sunset. There are no published observations of $\mathrm{NO}_{3}$ from space because this constituent is rapidly photodissociated during daytime and is not observable by solar occultation. It is shown that the $\mathrm{NO}_{2}$ mixing ratio reaches a maximum around $40 \mathrm{~km}$ with values between 14 and $16 \mathrm{ppbv}$ at low and middle latitudes. The global distribution of $\mathrm{NO}_{2}$ observed by GOMOS is very similar to the $\mathrm{NO}+\mathrm{NO}_{2}$ Halogen Occultation Experiment climatology deduced from sunset measurements from 1999 to 2004. At high latitude a high mixing ratio is observed in the north vortex in November 2003 after a strong solar proton event and in the south vortex in July 2003 . The $\mathrm{NO}_{3}$ mixing ratio peaks at $40-45 \mathrm{~km} . \mathrm{NO}_{3}$ follows a semiannual variation at low latitudes with maxima at equinoxes and an annual variation at middle and high latitudes with a maximum in summer. In the upper stratosphere the mixing ratio of $\mathrm{NO}_{3}$ is strongly correlated with temperature due to the thermal dependence of its formation rate.

Citation: Hauchecorne, A., et al. (2005), First simultaneous global measurements of nighttime stratospheric $\mathrm{NO}_{2}$ and $\mathrm{NO}_{3}$ observed by Global Ozone Monitoring by Occultation of Stars (GOMOS)/Envisat in 2003, J. Geophys. Res., 110, D18301, doi:10.1029/2004JD005711.

\section{Introduction}

[2] Odd nitrogen species play an important role in the photochemistry of stratospheric ozone. In the middle and upper stratosphere they participate in the catalytic destruction of ozone. In the lower stratosphere they form reservoir

\footnotetext{
${ }^{1}$ Service d'Aéronomie/Institut Pierre Simon Laplace, Centre National de la Recherche Scientifique, Verrières-le-Buisson, France.

${ }^{2}$ Finnish Meteorological Institute, Earth Observation, Helsinki, Finland.

${ }^{3}$ Belgian Institute for Space Aeronomy, Brussels, Belgium.

${ }^{4}$ ACRI-ST, Sophia-Antipolis, France.

${ }^{5}$ European Space Agency/European Space Research and Technology Centre, Noordwijk, Netherlands. Italy.

${ }^{6}$ European Space Agency/European Space Research Institute, Frascati,

${ }^{7}$ European Aeronautic Defence and Space-Astrium, Toulouse, France.

${ }^{8}$ Laboratoire de Physique et Chimie de l'Environnement, Centre National de la Recherche Scientifique, Orleans, France.

Copyright 2005 by the American Geophysical Union. 0148-0227/05/2004JD005711
}

species like $\mathrm{ClONO}_{2}$ which inhibit the efficiency of the catalytic destruction by halogen gases.

[3] The main source of $\mathrm{NO}_{2}$ is the photolysis of $\mathrm{N}_{2} \mathrm{O}$ by solar UV radiation. Other significant potential sources are the upward transport of $\mathrm{NO}_{2}$ produced by lightning in the tropical upper troposphere and the downward transport of NO from the thermosphere or the mesosphere in the winter polar vortex.

[4] $\mathrm{NO}_{2}$ profiles have been measured from space by several instruments. Most observations were performed using the solar occultation technique, Stratospheric Aerosol and Gas Experiment (SAGE) II [Cunnold et al., 1991], Halogen Occultation Experiment (HALOE) [Gordley et al., 1996], Polar Ozone and Aerosol Measurement (POAM) III [Randall et al., 2002], during sunrise or sunset when the concentration is changing very quickly, which makes the interpretation very difficult. Some others were obtained from the measurement of sunlight scattering at limb during daytime, Solar Mesospheric Experiment (SME) [Mount et al., 1984], Odin Spectrometer and IR Imager System 
(OSIRIS) [Sioris et al., 2003] and are not directly comparable with Global Ozone Monitoring by Occultation of Stars (GOMOS) due to the strong diurnal cycle of $\mathrm{NO}_{2}$. A few nighttime observations are available for limited periods. They were obtained from the detection of the limb infrared emission by Limb Infrared Monitor of the Stratosphere (LIMS) from October 1978 to May 1979 [Russell et al., 1988], Improved Stratospheric and Mesospheric Sounder (ISAMS) from September 1991 to July 1992 [Reburn et al., 1996] and Cryogenic Limb Array Etalon Spectrometer (CLAES) from October 1991 to May 1993 [Danilin et al., 1999]. Michelson Inteferometer for Passive Atmospheric Sounding (MIPAS) [Fischer and Oehlaf, 1996] on board Envisat is also providing such observations since July 2002. Local NO2 profiles are also obtained by several balloon-borne instruments including stellar and moon occultation spectrometers [Renard et al., 1996, 2001], a Michelson interferometer MIPAS-Balloon (MIPAS-B) [Friedl-Vallon et al., 2004]) and a Fourier transform interferometer Far Infrared Spectrometer (FIRS)-2 [Johnson et al., 1995].

[5] $\mathrm{NO}_{3}$ is a transition species for the transformation of $\mathrm{NO}_{2}$ into the $\mathrm{N}_{2} \mathrm{O}_{5}$ reservoir during night. There are no published observations of $\mathrm{NO}_{3}$ profiles because this species is rapidly photodissociated during daytime and is undetectable by solar occultation or limb scattering observation. SAGE III, launched in December 2001, has the capability to measure $\mathrm{NO}_{3}$ in moon occultation mode but the results are not yet published. A few local profiles were obtained up to $40 \mathrm{~km}$ at mid and high latitudes by balloon-borne stellar and moon occultation instruments [Renard et al., 1996, 2001].

[6] GOMOS, on board the European satellite Envisat launched 1 March 2002, is the first space instrument dedicated to the study of the atmosphere of the Earth by the technique of stellar occultation [Bertaux et al., 2004]. When a star sets behind the atmosphere, its light is absorbed by atmospheric constituents. Each constituent can be identified by its absorption spectrum. The atmospheric transmission spectrum is equal to the ratio between the star spectrum absorbed by the atmosphere and the reference star spectrum outside the atmosphere. As the reference spectrum is measured at the beginning of each occultation, we can consider GOMOS as a self-calibrated instrument, independent of any radiometric calibration. With four spectrometers, the wavelength coverage from $248 \mathrm{~nm}$ to $942 \mathrm{~nm}$ allows monitoring ozone, $\mathrm{H}_{2} \mathrm{O}, \mathrm{NO}_{2}$, $\mathrm{NO}_{3}$, atmospheric density from Rayleigh extinction, aerosols, $\mathrm{O}_{2}$ and temperature profiles from the upper troposphere to the mesosphere. Two additional fast photometers (1 kHz sampling rate) are used to correct star scintillation perturbations and to determine high vertical resolution temperature profiles.

[7] The main objective of the GOMOS/Envisat instrument is to build a very accurate global climatology of ozone and chemical species involved in ozone photochemistry. This climatology will be used to study the atmospheric natural variability, to test the validity of chemistry transport models and as a reference for future trend studies. GOMOS nighttime measurements are especially well adapted for this task due to their self-calibrating nature and the perfect knowledge of their altitude, a particularity of the star occultation technique. The goal of this paper is to present first simultaneous global measurements from space of nighttime $\mathrm{NO}_{2}$ and $\mathrm{NO}_{3}$ observed by GOMOS in 2003 .

\section{Data Processing}

[8] Results presented here are obtained using version V6.0 of the algorithms. This version has been implemented in April 2004 for the full reprocessing of 2003 data. It is not yet fully validated, especially for $\mathrm{NO}_{2}$ and $\mathrm{NO}_{3}$, due to the small number of available validation data in nighttime conditions. A few profiles have been compared with those of a balloon-borne moon occultation instrument in the frame of Atmospheric Chemistry Validation (ACVE2) by Renard et al. [2004]. They conclude that balloon and GOMOS profiles compare reasonably well on the average although GOMOS is not able to capture fine-scale vertical structures seen in balloon profiles. Further validation is needed to improve our confidence in the quality of GOMOS data. However, this kind of exercise is limited by the difficulty to find good coincidences in time and space and we consider very useful to present a full year of GOMOS $\mathrm{NO}_{2}$ band $\mathrm{NO}_{3}$ measurements even if they are not fully validated. Furthermore, the internal consistency of the data gives us confidence in their quality, at least for averaged profiles for which the random error is minimized. Our results will be available for comparison with those of other satellites instruments and with the outputs of chemistry transport models on a global basis.

[9] The main characteristics of the data inversion in V6.0 are summarized below. The inversion of spectrometer data from level $1 \mathrm{~b}$ (calibrated transmission spectra) to level 2 (vertical profiles of constituents) is made in two steps, the spectral inversion and the vertical inversion.

\subsection{Spectral Inversion}

[10] The goal of the spectral inversion is to determine the number of molecules along the line of sight (slant densities) of each absorber from the transmission spectrum corrected from refraction effects. In the prelaunch algorithm, a global spectral inversion was made simultaneously on all retrieved species $\left(\mathrm{O}_{3}, \mathrm{NO}_{2}, \mathrm{NO}_{3}\right.$, aerosols with a $1 / \lambda$ extinction dependence and air density) using a Levenberg-Marquardt nonlinear least square method [Press et al., 1986] to fit the measured transmission by the model transmission. More details are given by Kyrölä et al. [2004]. This global method was also used by Yee et al. [2002] for the inversion of UV and visible spectra from the Midcourse Space Experiment (MSX) satellite. It worked well for ozone at all altitudes and for minor species $\left(\mathrm{NO}_{2}\right.$ and $\left.\mathrm{NO}_{3}\right)$ above $40 \mathrm{~km}$. Below $40 \mathrm{~km}$, spectra are affected by scintillations due to smallscale atmospheric turbulent structures and vertical line density profiles of $\mathrm{NO}_{2}$ and $\mathrm{NO}_{3}$ exhibited often large unrealistic fluctuations. In order to solve this problem, a differential optical absorption spectroscopy (DOAS) method was implemented in V6.0 for these two species. The DOAS principle is to determine the densities of trace gases by measuring their specific narrow band absorption structures [Platt, 1994]. In our case, the differential spectrum is obtained by removing a $15 \mathrm{~nm}(30 \mathrm{~nm})$ moving average respectively for $\mathrm{NO}_{2}\left(\mathrm{NO}_{3}\right)$. The temperature dependence of 
$\mathrm{NO}_{2}$ and $\mathrm{NO}_{3}$ cross sections is taken into account using ECMWF temperatures along the line of sight.

\subsection{Vertical Inversion}

[11] The goal of the vertical inversion is to compute local density profiles as a function of altitude from slant density profiles as a function of tangent altitude. In the prelaunch algorithm, the vertical inversion was made using an onion peeling method with a linear interpolation between layers. This method may amplify oscillations due to noisy data and scintillations, especially in the bottom of the profiles where the altitude sampling is reduced by the refraction. In order to attenuate this effect, a Tikhonov inversion technique with a second difference smoothness constraint [Kyrölä et al., 1993] is applied in V6.0 with a constant vertical resolution fixed to $4 \mathrm{~km}$ in the case of $\mathrm{NO}_{2}$ and for $\mathrm{NO}_{3} \mathrm{~A}$ similar method was used by Yee et al. [2002]. It is worth to note that this method does not use an a priori profile.

\subsection{Data Accuracy}

[12] The uncertainty on local densities includes a random part due to photon counting, detector noise and chromatic scintillation effect and a systematic part due to uncertainties in the data processing parameters (cross sections, instrument spectral resolution). The random error depends on the brightness of the star in the spectral range of strongest absorption by the retrieved species $\left(400-450 \mathrm{~nm}\right.$ for $\mathrm{NO}_{2}$ and $630-670 \mathrm{~nm}$ for $\mathrm{NO}_{3}$ ). These two spectral bands are not too far from $550 \mathrm{~nm}$ used for the definition of the visual magnitude. If we consider only the 70 brightest stars (visual magnitude $<2.25$ ), the random error of an individual profile is not larger than $20 \%$ for $\mathrm{NO}_{2}$ between 25 and $45 \mathrm{~km}$ and $30 \%$ for $\mathrm{NO}_{3}$ between 30 and $45 \mathrm{~km}$ and increases to $40 \%$ at $50 \mathrm{~km}$ and $20 \mathrm{~km}$ for $\mathrm{NO}_{2}$ and $60 \%$ at $50 \mathrm{~km}$ and $25 \mathrm{~km}$ for $\mathrm{NO}_{3}$ and higher values above and below these altitude ranges. For this study, we limit the data analysis to 20 $50 \mathrm{~km}$ for $\mathrm{NO}_{2}$ and $25-50 \mathrm{~km}$ for $\mathrm{NO}_{3}$. Outside these altitude ranges GOMOS data have to be considered with caution. The systematic error is more difficult to estimate. Uncertainties in cross sections and on their dependence on temperature may have a significant contribution to the error budget. Vandaele et al. [2002] report up to 7\% differences between $\mathrm{NO}_{2}$ cross sections measured by different groups and Orphal et al. [2003] mention up to $10 \%$ differences for $\mathrm{NO}_{3}$. For the present study, we use monthly mean profile in $15^{\circ}$ latitude bands resulting from the average of 100 500 individual profiles. The random error is reduced to only a few percent (inversely proportional to the square root of the number of profiles) and the total error budget is dominated by systematic errors which are not or less reduced by the averaging process. It can be roughly estimated to $10 \%$ for $\mathrm{NO}_{2}$ and $15 \%$ for $\mathrm{NO}_{3}$.

\section{Data Selection and Averaging}

[13] One difficulty of the stellar occultation technique is the sensitivity of the data quality to star characteristics (brightness, temperature) and to viewing geometry (sun azimuth and elevation, occultation obliquity). Furthermore, for a given star, the latitude of the tangent point depends on the day of the year and the latitude coverage changes with time. In order to build three-dimensional $\mathrm{NO}_{2}$ and $\mathrm{NO}_{3}$ fields as homogeneous as possible, a three-step selection and averaging procedure is applied. (1) We use only the 70 brightest stars and we discard daylight observations to eliminate too noisy $\mathrm{NO}_{2}$ and $\mathrm{NO}_{3}$ profiles. (2) For a given star and during 1 day, the latitude of the tangent point is almost constant and the star is occulted 14 or 15 times (once per orbit) with a $25^{\circ}$ westward longitude shift per orbit. A daily mean profile is computed as the weighted average of all available profiles amongst the $14-15$ ones. Weights are inversely proportional to the squared inverse error estimates. Each daily mean profile can be considered as a zonal average at the mean latitude of the tangent point. (3) All daily mean profiles for 1 month and within a $15^{\circ}$ latitude band are averaged taking into account their weights as indicated in step 2.

\section{Results and Discussion}

\section{1. $\mathrm{NO}_{2}$}

[14] Partitioning of odd nitrogen family, defined as $\mathrm{NO}+$ $\mathrm{NO}_{2}+\mathrm{NO}_{3}+\mathrm{N}_{2} \mathrm{O}_{5}$, is controlled in the stratosphere by the fast photochemical equilibrium between $\mathrm{NO}$ and $\mathrm{NO}_{2}$ and the slow photodissociation of $\mathrm{N}_{2} \mathrm{O}_{5}$ during daytime and the slow conversion of $\mathrm{NO}_{2}$ into $\mathrm{NO}_{3}$ and then into $\mathrm{N}_{2} \mathrm{O}_{5}$ during nighttime. Owing to these photochemical reactions, the $\mathrm{NO}_{2}$ concentration is never constant. It is slowly decreasing by night and increasing by day and rapidly increasing at sunset and decreasing at sunrise. It is therefore very important to take into account the local time when comparing measurements made by different instruments. In the case of GOMOS, nighttime observations are made during the ascending path of Envisat and the local time is approximately equal to the local hour of the ascending node, 1000 LT.

[15] GOMOS provides $\mathrm{NO}_{2}$ vertical profiles in absolute concentration as a function of geometric altitude. For photochemistry studies and comparison with other measurements and models, it is more convenient to consider mixing ratios. Figure 1 shows latitude-altitude maps of $\mathrm{NO}_{2}$ for each month in 2003 except May where very few measurements are available due to a failure in the star pointing system. Mixing ratios have been computed using European Centre for Medium-Range Weather Forecasts (ECMWF) pressure and temperature interpolated to the time and location of GOMOS measurements. At mid and low latitudes, a maximum in the vertical profile is observed around $40 \mathrm{~km}$ in both hemispheres. The peak value ranges from 14 to $16 \mathrm{ppbv}$ depending on the month and its latitude location varies between $20^{\circ} \mathrm{S}$ and $20^{\circ} \mathrm{N}$ with a shift toward the summer/autumn hemisphere, to the south from February to April and to the north from August to November. This value is slightly smaller than the results of Reburn et al. [1996] who found a 17 ppbv peak of nighttime $\mathrm{NO}_{2}$ around $3 \mathrm{hPa}(\sim 40 \mathrm{~km})$ in ISAMS and LIMS January data at equatorial and south tropical latitudes. At high latitude, lower values are observed in general, except when a strong descent of air enriched in $\mathrm{NO}_{x}\left(\mathrm{NO}+\mathrm{NO}_{2}\right)$ of mesospheric or thermospheric origin occurs inside the winter polar vortex. It is interesting to note the strong peak of $\mathrm{NO}_{2}$ above $38 \mathrm{~km}$, with up to $38 \mathrm{ppbv}$ at $50 \mathrm{~km}$, in the northern high latitude upper stratosphere in November. This peak has been attributed by Seppälä et al. [2004] to the formation of 

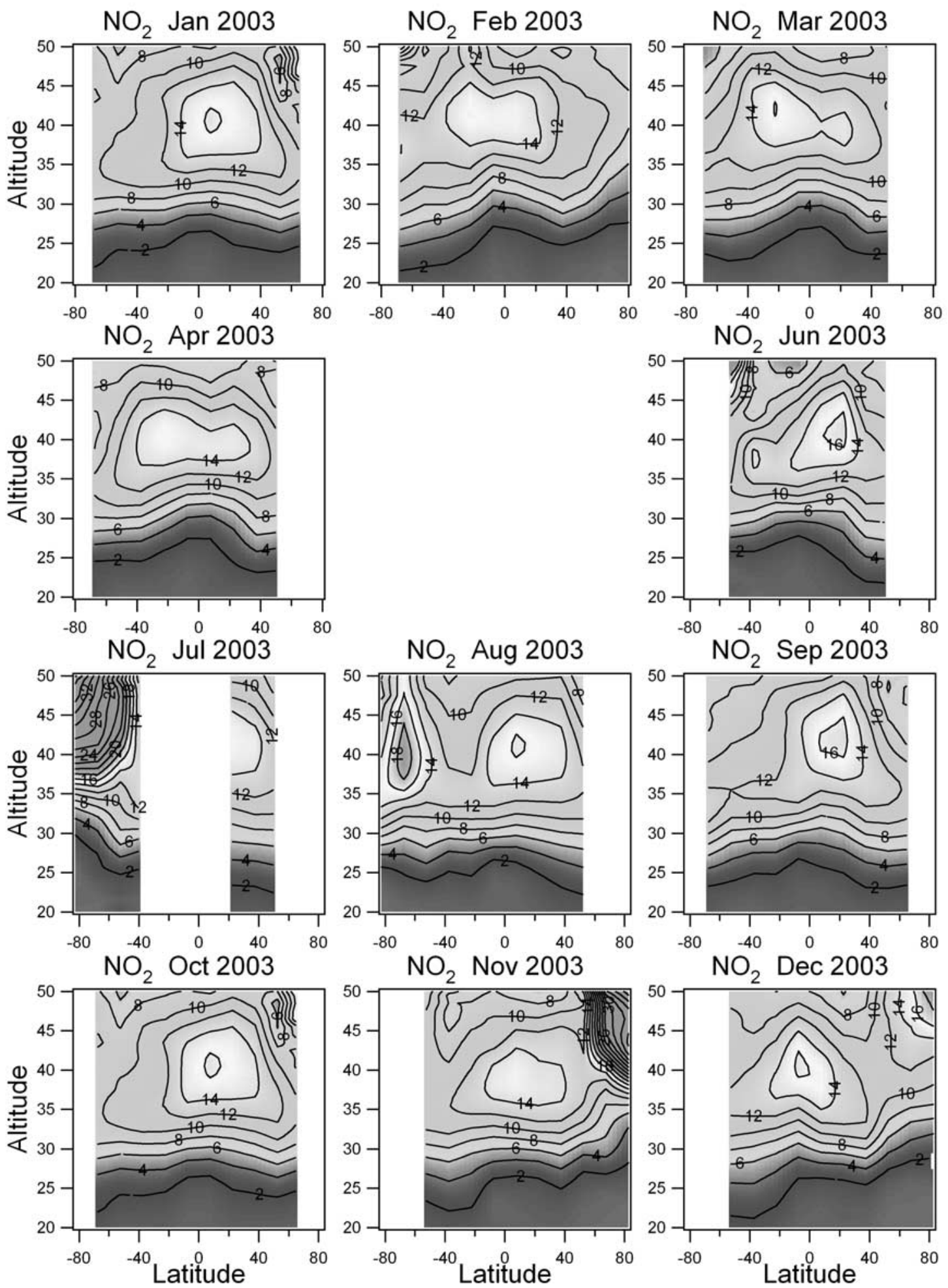

Figure 1. Latitude-altitude maps of $\mathrm{NO}_{2}$ mixing ratio in ppbv for each month in 2003. See color version of this figure in the HTML.

a large amount of $\mathrm{NO}_{x}$ during the very intense solar proton event at the end of October 2003. Such $\mathrm{NO}_{2}$ enhancement after strong solar proton events have been observed and simulated in the past [Jackman et al., 2000, 2001; Verronen et al., 2002]. A very high mixing ratio (up to $36 \mathrm{ppbv}$ at
$50 \mathrm{~km}$ ) is also detected in July at southern high latitude. It is probably be due to the strong diabatic descent of mesospheric and thermospheric air with high $\mathrm{NO}_{x}$ mixing ratio in the southern winter polar vortex and a contribution of two moderate solar proton events occurring on 28-30 May and 

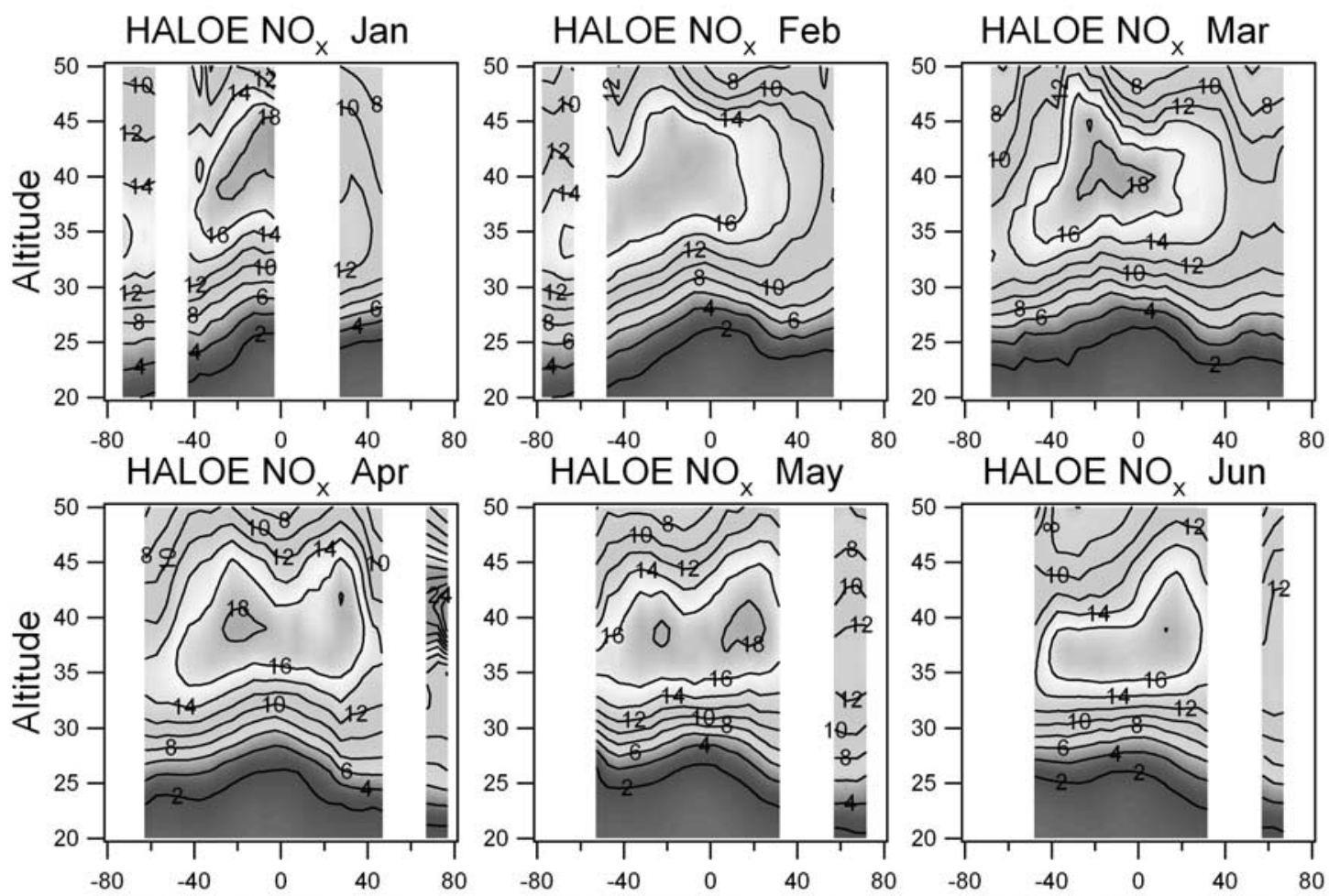

HALOE $\mathrm{NO}_{x}$ May

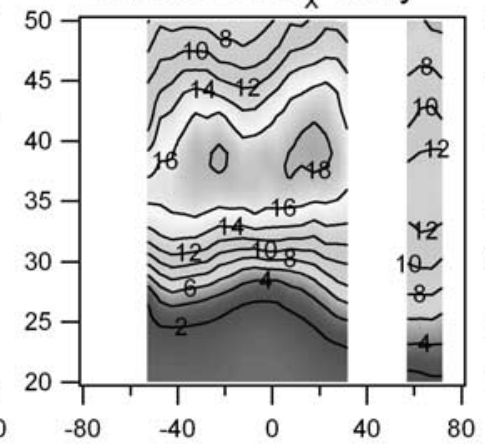

HALOE $\mathrm{NO}_{x}$ Jun

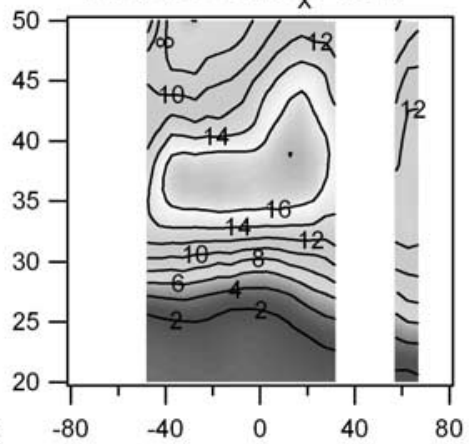

HALOE NO ${ }_{x}$ Jul

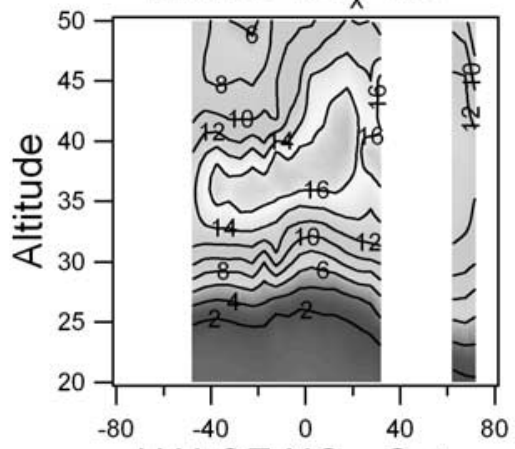

HALOE NO ${ }_{x}$ Aug

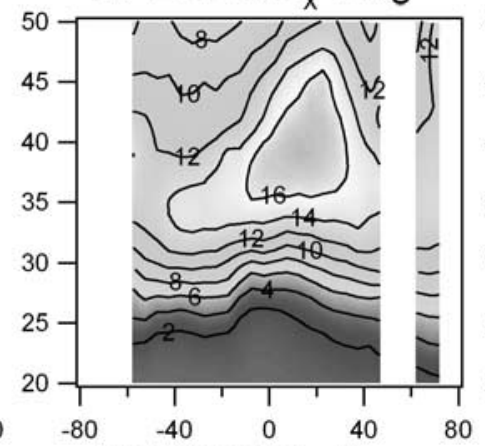

HALOE NO $\mathrm{Nep}$

HALOE NO $\mathrm{NO}_{x}$ Oct

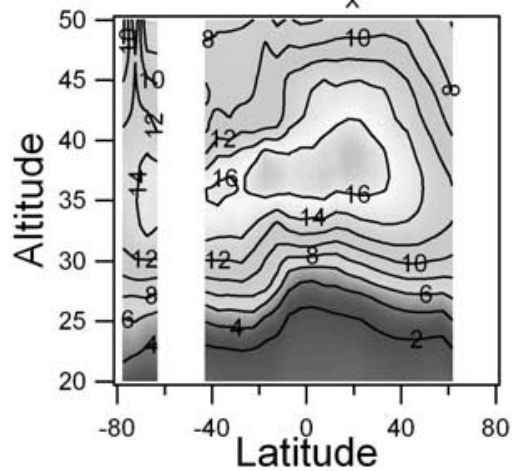

HALOE NO ${ }_{x}$ Nov
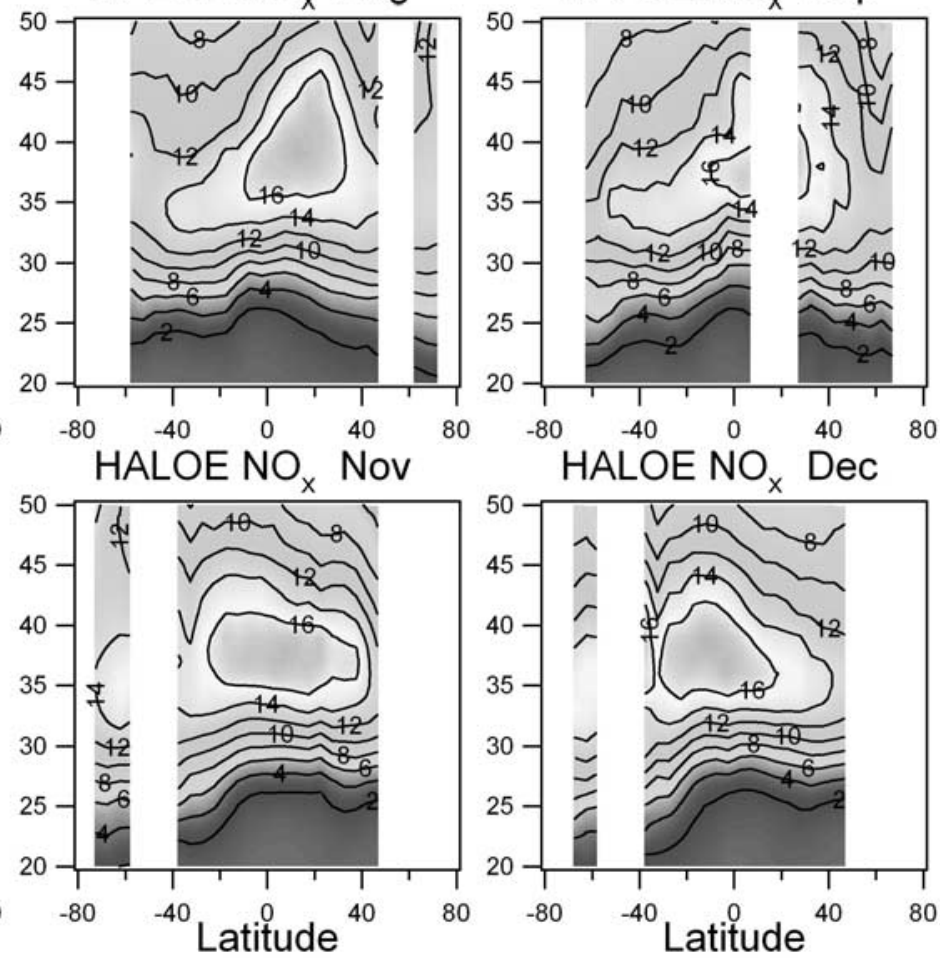

HALOE NO ${ }_{x}$ Dec

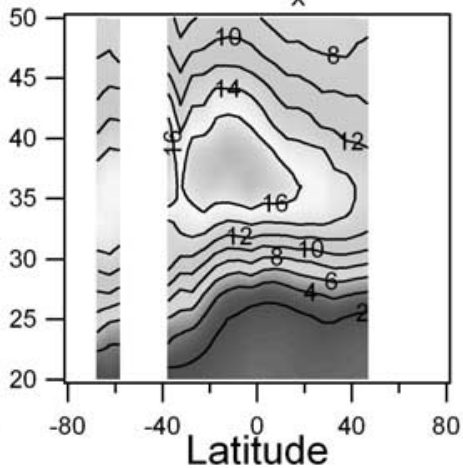

Figure 2. Latitude-altitude maps of Halogen Occultation Experiment (HALOE) $\mathrm{NO}_{x}\left(\mathrm{NO}+\mathrm{NO}_{2}\right)$ mixing ratio at sunset in ppbv for each month (average from 1999 to 2004). See color version of this figure in the HTML.

18 June is not excluded. Further studies are needed to analyze and interpret these observations in cooperation with modelers.

[16] Our understanding of the global climatology of NO and $\mathrm{NO}_{2}$ is largely based today on solar occultation instru- ments. It is then very interesting to compare our results with those of a well validated solar instrument. A reasonable comparison can be made with HALOE sunset $\mathrm{NO}+\mathrm{NO}_{2}$ data. By sunset, most of the $\mathrm{N}_{2} \mathrm{O}_{5}$ reservoir has been converted to $\mathrm{NO}$ and $\mathrm{NO}_{2}$. Shortly after sunset the $\mathrm{NO}$ is 


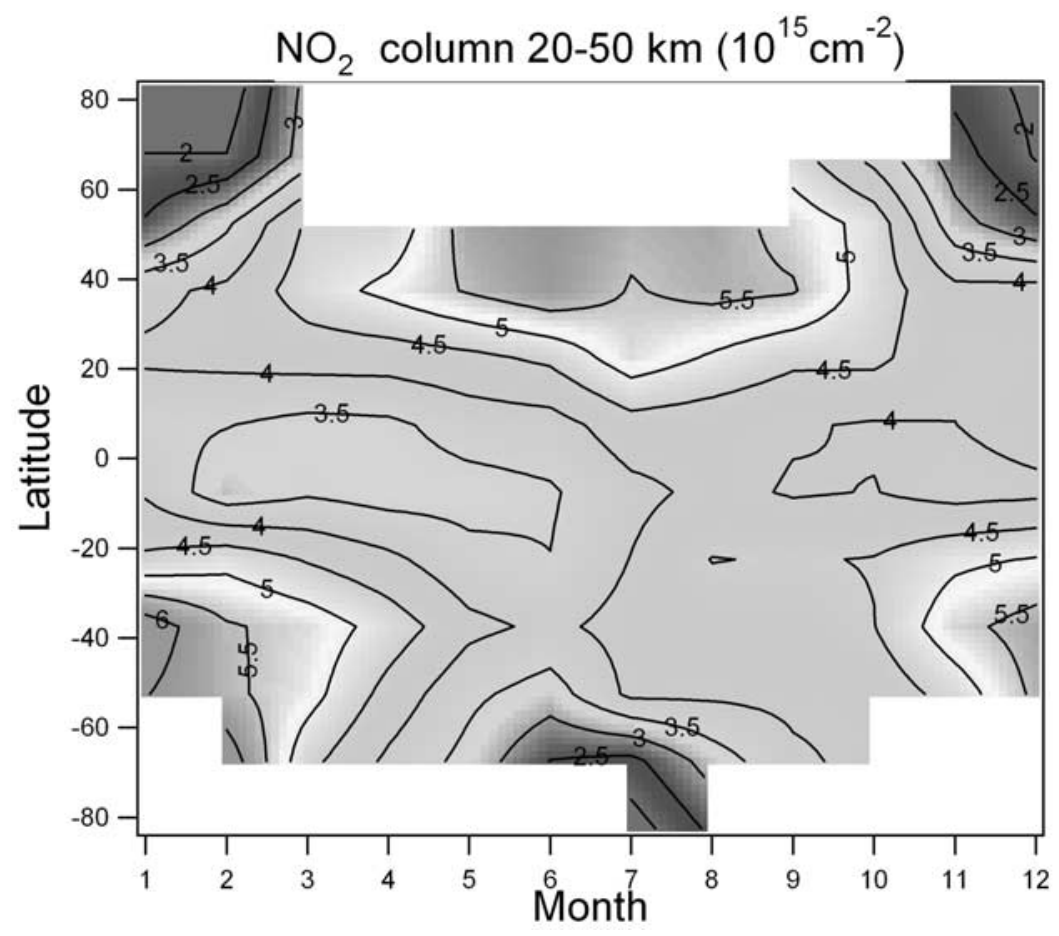

Figure 3. Time-latitude cross section of $\mathrm{NO}_{2}$ stratospheric column $(20-50 \mathrm{~km})$ in $10^{15} \mathrm{~cm}^{-2}$ in 2003. See color version of this figure in the HTML.

converted to $\mathrm{NO}_{2}$, which then converts slowly to $\mathrm{N}_{2} \mathrm{O}_{5}$ during the night. Thus the sum $\mathrm{NO}+\mathrm{NO}_{2}$ at sunset is a reasonable proxy for the $\mathrm{NO}_{2}$ that GOMOS measures at 1000 LT. A $\mathrm{NO}_{x}$ climatology, built from HALOE sunset data from 1999 to 2004, extracted from the Web site http:// haloedata.larc.nasa.gov/home/index.php, is presented in Figure 2. A direct comparison with HALOE data in 2003 was not possible due to too many data gaps. At low and mid latitudes, peak mixing ratios range from 16 to $18 \mathrm{ppmv}$, about 2 ppmv higher than in GOMOS $\mathrm{NO}_{2}$. This may be explained by the slow conversion of $\mathrm{NO}_{2}$ into $\mathrm{N}_{2} \mathrm{O}_{5}$ between sunset and 1000 LT. It is very interesting to note that the location and the shape of the maximum presents many similarities between both data sets, for instance the shift of the maximum toward the summer/autumn hemisphere and the double peak structure from March to June. At high latitude, high values observed by GOMOS are not visible in HALOE data. This may be due to the fact that they are caused by specific phenomena occurring only in 2003 like the October 2003 solar proton event or to the limited HALOE coverage at high latitudes in winter. Several space-borne instruments, as well as many ground-based UV-visible spectrometers, provide daily total columns of $\mathrm{NO}_{2}$. For future comparison with such observations and for geophysical studies, GOMOS $\mathrm{NO}_{2}$ stratospheric columns are computed by integration of profile concentrations between 20 and $50 \mathrm{~km}$. This altitude range is chosen to integrate most of stratospheric $\mathrm{NO}_{2}$ and to avoid too noisy data at low altitude. Contrary to mixing ratios that are maximum around $40 \mathrm{~km}$, altitudes lower than $35 \mathrm{~km}$ contribute to 70 to $80 \%$ to the column. At midlatitude, $\mathrm{NO}_{2}$ columns (Figure 3) follow a strong annual cycle with a maximum $>6.010^{15} \mathrm{~cm}^{-2}$ in summer and a minimum $<310^{15} \mathrm{~cm}^{-2}$ in winter. Low values are observed at high latitude in winter $\left(<2.010^{15} \mathrm{~cm}^{-2}\right)$ in relation to the conversion of $\mathrm{NO}_{2}$ into $\mathrm{N}_{2} \mathrm{O}_{5}$ in the polar night and to the heterogeneous conversion of $\mathrm{NO}_{x}$ into $\mathrm{HNO}_{3}$ [Goutail et al., 1994] in presence of polar stratospheric clouds. At low latitude, a weak annual variation is observed, in phase in the two hemispheres, with a minimum from February to April and a maximum from August to January.

\section{2. $\mathrm{NO}_{3}$}

[17] The nighttime $\mathrm{NO}_{3}$ concentration is controlled by the three reactions [Brasseur and Solomon, 1986]

$$
\begin{gathered}
\mathrm{NO}_{2}+\mathrm{O}_{3} \rightarrow \mathrm{NO}_{3}+\mathrm{O}_{2}, \\
\mathrm{NO}_{2}+\mathrm{NO}_{3}+\mathrm{M} \rightarrow \mathrm{N}_{2} \mathrm{O}_{5}+\mathrm{M}, \\
\mathrm{N}_{2} \mathrm{O}_{5} \rightarrow \mathrm{NO}_{2}+\mathrm{NO}_{3} .
\end{gathered}
$$

Below $40 \mathrm{~km}$, the thermal decomposition (reaction (3)) can be neglected and reaction (2) is fast enough for $\mathrm{NO}_{3}$ to reach steady state equilibrium in less than 1 hour after sunset typically. $\mathrm{NO}_{3}$ concentration is proportional to $\mathrm{O}_{3}$ and is positively correlated with temperature through reaction (1). As pointed out by Renard et al. [2005], this strong dependence on temperature may induce biases in individual vertical $\mathrm{NO}_{3}$ profiles in the presence of local temperature fluctuations. However, monthly mean profiles will not be too much affected. Above $40 \mathrm{~km}$, the thermal decomposition is a significant source of $\mathrm{NO}_{2}$ after sunset and reaction (2) is much slower. As a result, $\mathrm{NO}_{3}$ is no more 

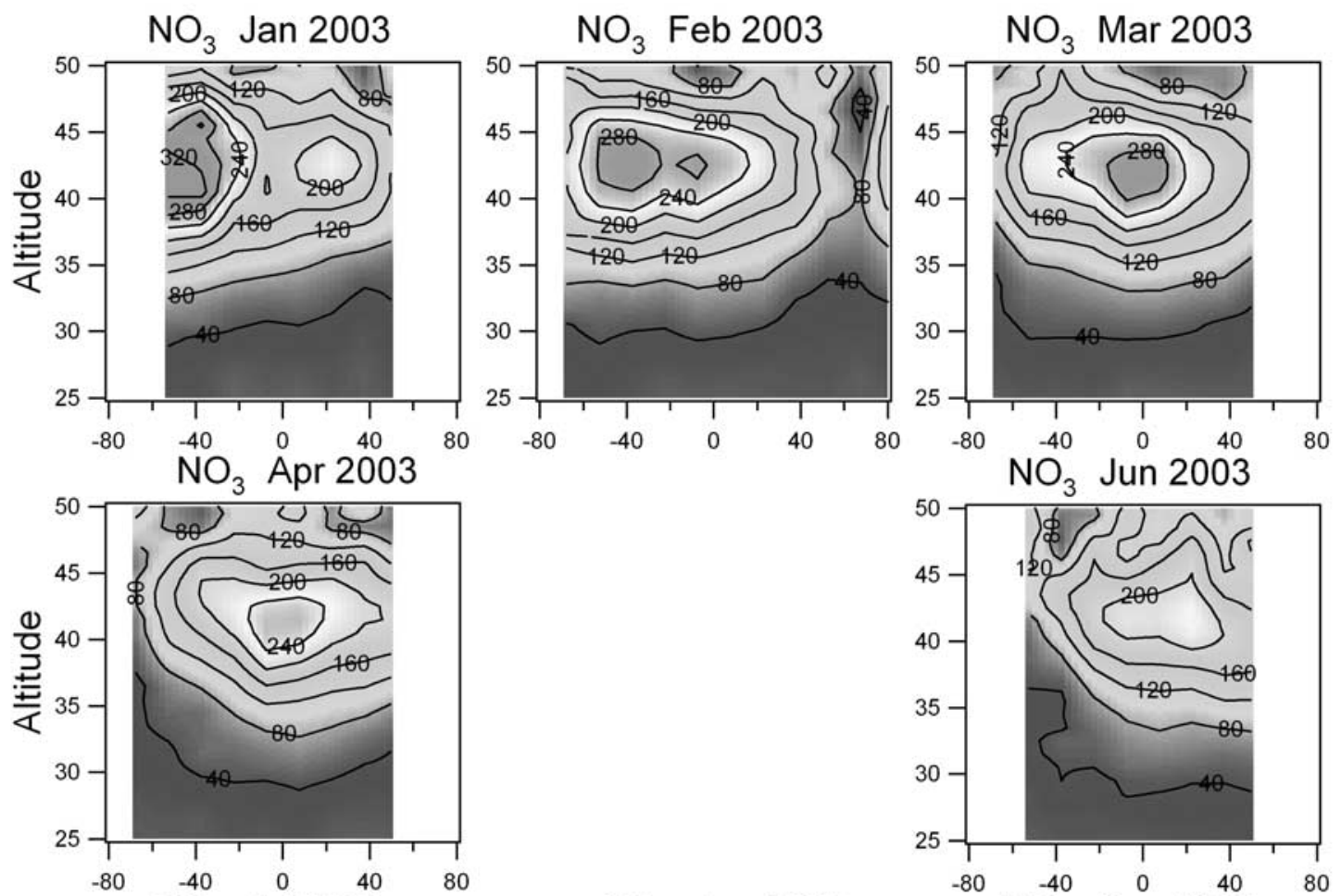

$\mathrm{NO}_{3}$ Jul 2003
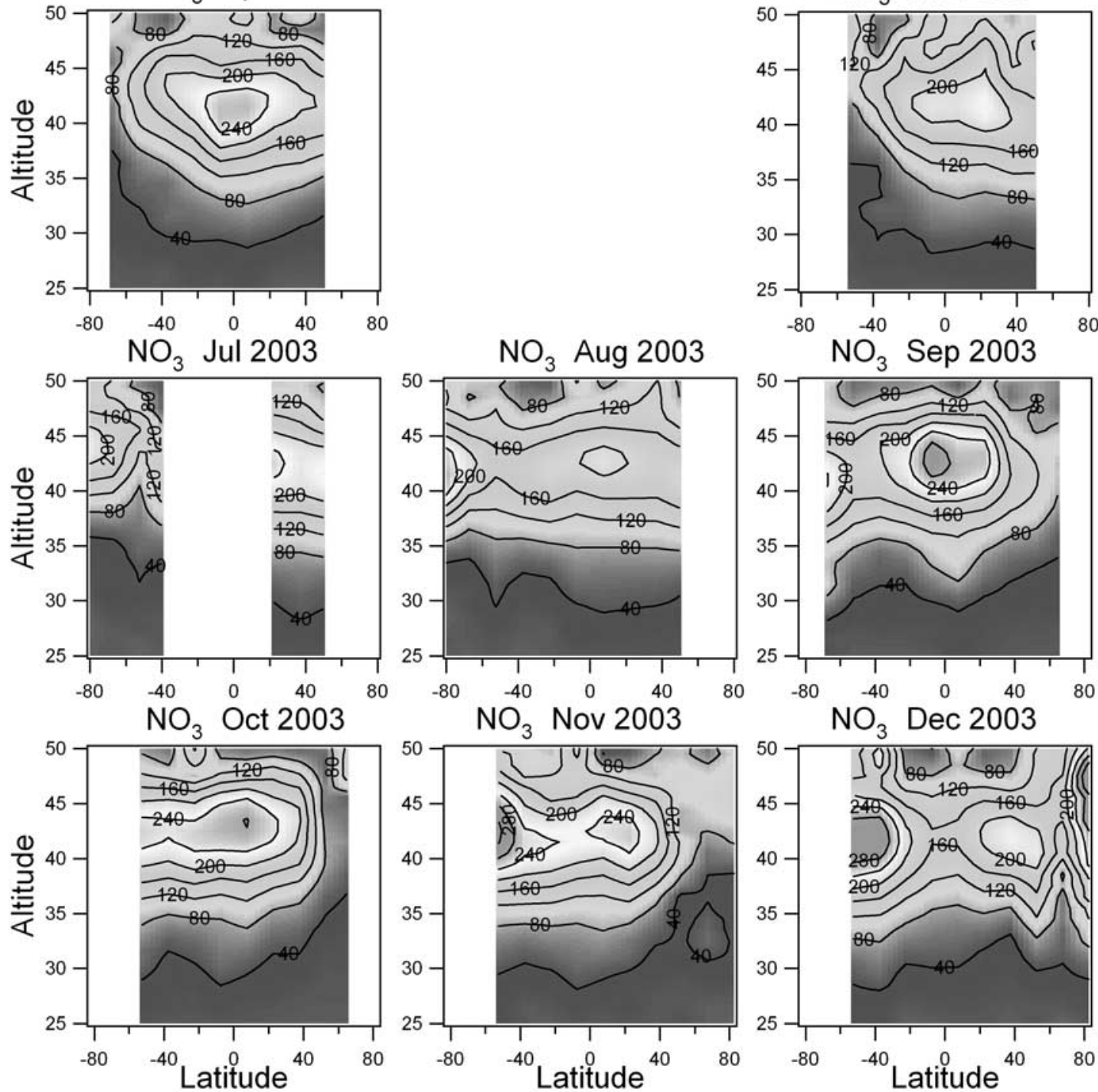

Figure 4. Latitude-altitude cross section of $\mathrm{NO}_{3}$ mixing ratio in pptv for each month in 2003. See color version of this figure in the HTML.

at equilibrium at the time of GOMOS observations [Marchand et al., 2004] and is dependent on both $\mathrm{NO}_{2}$ and $\mathrm{O}_{3}$ concentrations.

[18] The maximum mixing ratio is reached between 41 and $43 \mathrm{~km}$ (Figure 4). At mid latitude, values are higher in the summer hemisphere than in the winter one (up to
320 pptv at southern midlatitude in January). At low latitudes, the variation is more semiannual with maxima in February-March and September and minima in December-January and June-August. High values are observed at northern high latitudes in the north in December at the time of a sudden stratospheric warming. 

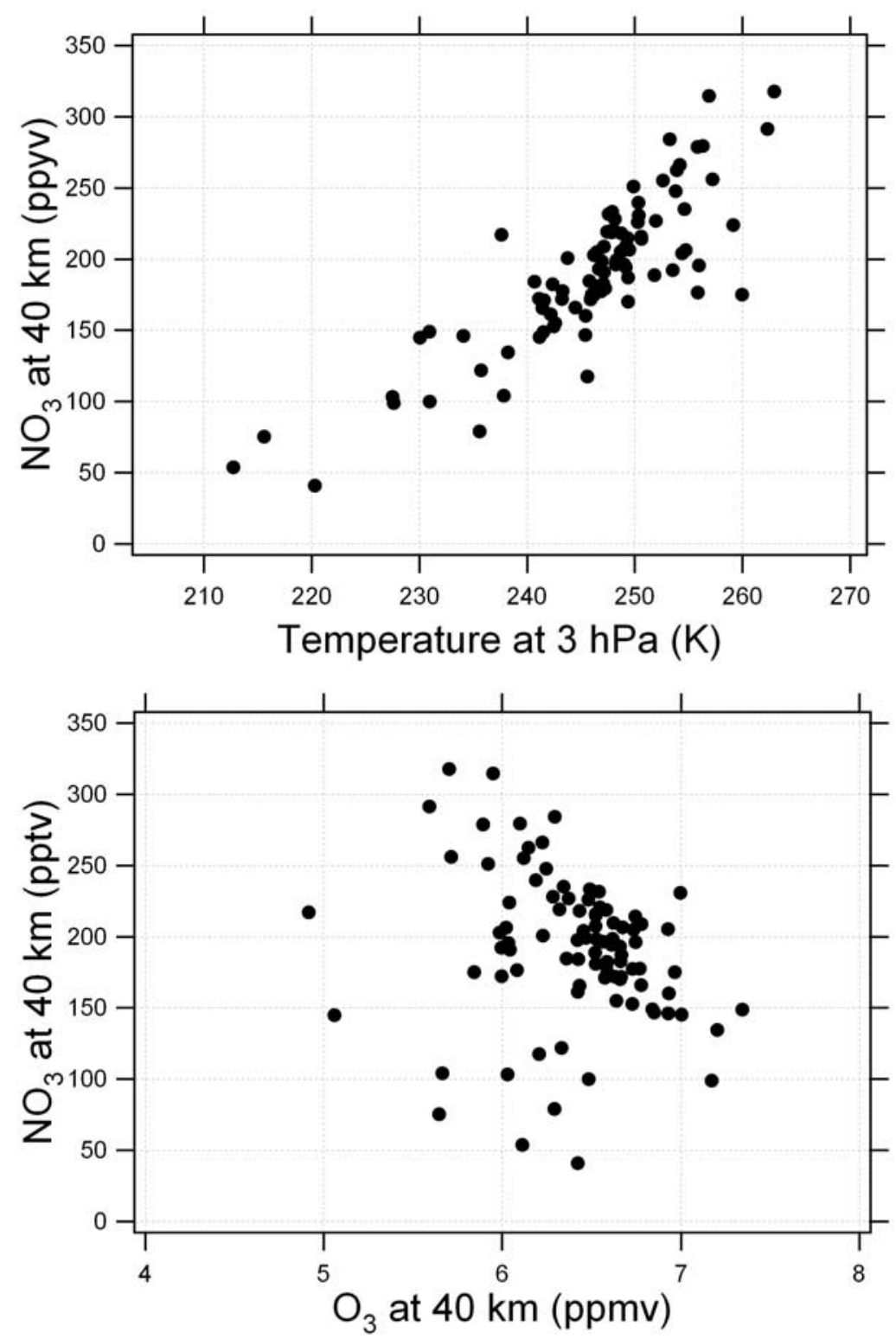

Figure 5. (top) $\mathrm{NO}_{3}$ mixing ratio at $40 \mathrm{~km}$ versus European Centre for Medium-Range Weather Forecasts (ECMWF) temperature at $3 \mathrm{hPa}(\sim 40 \mathrm{~km})$. (bottom) $\mathrm{NO}_{3}$ mixing ratio at $40 \mathrm{~km}$ versus $\mathrm{O}_{3}$ mixing ratio at $40 \mathrm{~km}$ for all monthly averaged latitude binned data between $60^{\circ} \mathrm{S}$ and $60^{\circ} \mathrm{N}$.

All these results suggest that $\mathrm{NO}_{3}$ evolution is linked with upper stratospheric temperature. Warmer temperatures increase the production rate of $\mathrm{NO}_{3}$ through the temperature dependence of reaction (1). To test this hypothesis, the monthly average of ECMWF temperature at $3 \mathrm{hPa}(\sim 40 \mathrm{~km})$ has been computed for each $15^{\circ}$ latitude band between $60^{\circ} \mathrm{S}$ and $60^{\circ} \mathrm{N}$ and correlated with the corresponding $\mathrm{NO}_{3}$ mixing ratio (Figure 5 (top)). There is a very clear correlation between both parameters. On the contrary, $\mathrm{NO}_{3}$ at $40 \mathrm{~km}$ does not seem to be correlated with $\mathrm{O}_{3}$ at $40 \mathrm{~km}$ (Figure 5 (bottom)) which is almost constant at this altitude. Another mechanism may contribute to high $\mathrm{NO}_{3}$ values at northern high latitudes in December. Orsolini et al. [2005] attribute the large $\mathrm{HNO}_{3}$ increase observed by MIPAS at this time to the strong increase of $\mathrm{NO}_{y}$ in the Arctic upper stratosphere after the October 2003 solar proton event. This increase will enhance the production of $\mathrm{NO}_{3}$ through reaction (1). Further studies are needed to evaluate the contribution of the two proposed mechanisms.

[19] $\mathrm{NO}_{3}$ stratospheric columns have been computed by integration of concentration profiles in the limited altitude range $25-50 \mathrm{~km}$ in order to avoid too noisy data in the lower stratosphere. The seasonal evolution of the column as a function of latitude is quite similar to the evolution of the peak mixing ratio (Figure 6). A strong annual variation is observed at mid and high latitudes with a summer maximum higher in the south than in the north. In the north, the effect of the December polar stratospheric warming is also visible in the column. At low latitude, the evolution is more 


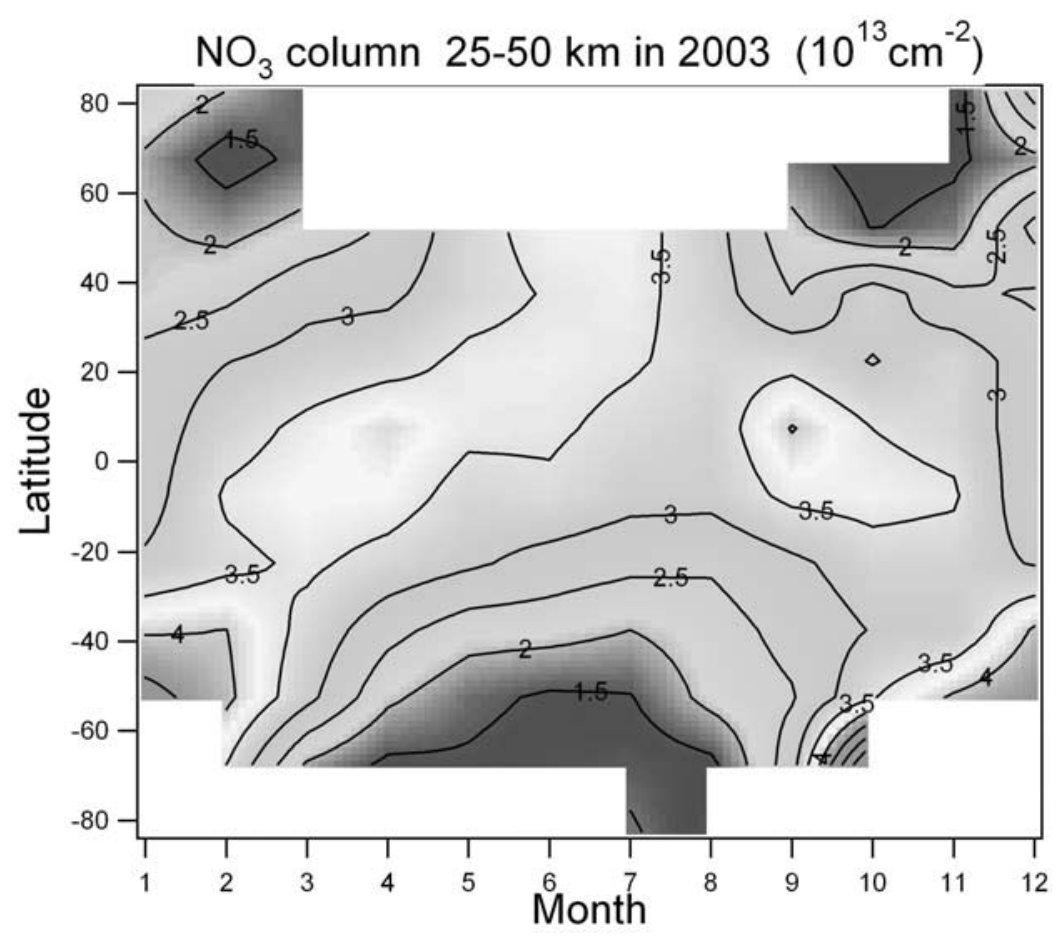

Figure 6. Time-latitude cross section of $\mathrm{NO}_{3}$ stratospheric column $(25-50 \mathrm{~km})$ in $10^{13} \mathrm{~cm}^{-2}$ in 2003. See color version of this figure in the HTML.

semiannual with maxima in March-April and SeptemberOctober and minima in December-January and June-July.

\section{Conclusion}

[20] GOMOS provides for the first time simultaneous global measurements of stratospheric $\mathrm{NO}_{2}$ and $\mathrm{NO}_{3}$ during night. The full reprocessing of 2003 data allowed us to follow the seasonal evolution of these two species as a function of latitude. The main results of this study are summarized below.

[21] 1. For $\mathrm{NO}_{2}$, at low and mid latitudes, the mixing ratio reaches a maximum around $40 \mathrm{~km}$ with 14 to $16 \mathrm{ppbv}$. These values are about 2 ppbv lower than the sum NO + $\mathrm{NO}_{2}$ measured by HALOE at sunset. The difference can be explained by the slow conversion of $\mathrm{NO}_{2}$ into $\mathrm{N}_{2} \mathrm{O}_{5}$ between sunset and 10pm local time. The location of the maximum is shifted toward the summer/autumn hemisphere in both data sets. A high mixing ratio is also observed in upper stratosphere in November in the north polar vortex after a strong solar proton event and in July in the south vortex when air enriched in $\mathrm{NO}_{x}$ descends from the mesosphere and the thermosphere. At low latitude, $\mathrm{NO}_{2}$ stratospheric columns follow an annual variation in phase in the two hemispheres with a minimum from February to April and a maximum from August to January. At middle and high latitudes, the annual cycle of $\mathrm{NO}_{2}$ columns is of large amplitude with a maximum in summer.

[22] 2. For $\mathrm{NO}_{3}$, the mixing ratio peaks at $40-45 \mathrm{~km}$. At low latitude, a semiannual variation is observed in $\mathrm{NO}_{3}$ peak concentration and stratospheric column with a maximum at equinoxes. At middle and high latitudes, the variation of $\mathrm{NO}_{3}$ is annual with a maximum in summer.
The $\mathrm{NO}_{3}$ mixing ratio in the upper stratosphere is strongly correlated with temperature through the thermal dependence of reaction $\mathrm{NO}_{2}+\mathrm{O}_{3} \rightarrow \mathrm{NO}_{3}+\mathrm{O}_{2}$.

[23] These results are still preliminary and more validation studies will be done in the future but they provide a first full global view of two important odd nitrogen species. They are available for model studies to test photochemistry on $\mathrm{NO}_{x}$ in the stratosphere and for comparison with other satellite, in situ and ground-based observations. One of the main advantages of GOMOS is a better geographical coverage than solar occultation instruments upon which so much of our understanding today is based.

[24] Acknowledgments. Envisat is a European Space Agency (ESA) mission. We are especially grateful for the tremendous work of Guido Levrini and Jacques Louet for the success of the mission.

\section{References}

Bertaux, J.-L., et al. (2004), First results on GOMOS/ENVISAT, Adv. Space Res., 33, 1029-1035.

Brasseur, G., and S. Solomon (1986), Aeronomy of the Middle Atmosphere, D. Reidel, Norwell, Mass.

Cunnold, D. M., et al. (1991), Validation of SAGE II NO 2 measurements, J. Geophys. Res., 96, 12,913-12,925.

Danilin, M. Y., et al. (1999), Nitrogen species in the post-Pinatubo stratosphere: Model analysis utilizing UARS measurements, J. Geophys. Res., 104, 8247-8262.

Fischer, H., and H. Oehlaf (1996), Remote sensing of vertical profiles of atmospheric trace constituents with MIPAS limb-emission spectrometers, Appl. Opt., 35, 2796-2797.

Friedl-Vallon, F., G. Maucher, A. Kleinert, A. Lengel, C. Keim, H. Oehlaf, H. Fischer, M. Seefeldner, and O. Trieschmann (2004), Design and characterization of the balloon-borne Michelson Interferometer for Passive Atmospheric Sounding, Appl. Opt., 43, 3335-3355.

Gordley, L. L., et al. (1996), Validation of nitric oxide and nitrogen dioxide measurements made by Halogen Occultation Experiment for UARS platform, J. Geophys. Res., 101, 10,241-10,266. 
Goutail, F., J.-P. Pommereau, A. Sarkissian, E. Kyro, and V. Dorokhoy (1994), Total nitrogen dioxide at the Arctic polar circle since 1990 Geophys. Res. Lett., 21, 1371-1374.

Jackman, C. H., E. L. Fleming, and F. M. Vitt (2000), Influence of extremely large solar proton events in a changing stratosphere, J. Geophys. Res., 105, 11,659-11,670.

Jackman, C. H., R. D. McPeters, G. J. Labow, E. L. Fleming, C. J. Praderas, and J. M. Russell (2001), Northern Hemisphere atmospheric effects due to the July 2000 solar proton event, Geophys. Res. Lett., 28, 2883-2886.

Johnson, D. G., K. W. Jucks, W. A. Traub, and K. V. Chance (1995), The Smithsonian Far-Infrared Spectrometer and data reduction system, J. Geophys. Res., 100, 3091-3106.

Kyrölä, E., E. Sihvola, Y. Kotivuori, M. Tikka, and T. Tuomi (1993), Inverse theory for occultation measurements: 1. Spectral inversion, J. Geophys. Res., 98, 7367-7381.

Kyrölä, E., et al. (2004), GOMOS on Envisat: An overview, Adv. Space Res., 33, 1020-1028.

Marchand, M., S. Bekki, A. Hauchecorne, and J.-L. Bertaux (2004), Validation of the self-consistency of GOMOS $\mathrm{NO}_{3}, \mathrm{NO}_{2}$ and $\mathrm{O}_{3}$ using chemical datam assimilation, Geophys. Res. Lett., 31, L10107, doi:10.1029/2004GL019631.

Mount, G. H., D. W. Rusch, J. F. Noxon, J. M. Zawodny, and C. A. Barth (1984), Measurements of stratospheric $\mathrm{NO}_{2}$ from solar mesosphere explorer satellite: 1. An overview of the results, J. Geophys. Res., 89, $1327-1340$

Orphal, J., C. E. Fellows, and P.-M. Flaud (2003), The visible absorption spectrum of $\mathrm{NO}_{3}$ measured by high-resolution Fourier transform spectroscopy, J. Geophys. Res., 108(D3), 4077, doi:10.1029/2002JD002489.

Orsolini, Y. J., G. L. Manney, M. L. Santey, and C. E. Randall (2005), An upper stratospheric layer of enhanced $\mathrm{HNO}_{3}$ following exceptional solar storms, Geophys. Res. Lett., 32, L12S01, doi:10.1029/2004GL021588.

Platt, U. (1994), Differential optical absorption spectroscopy (DOAS), Chem. Anal. Ser., 127, 27-83.

Press, W. H., B. P. Flannery, S. A. Teulosky, and W. T. Vetterling (1986), Numerical Recipes: The Art of Scientific Computing, Cambridge Univ. Press, New York.

Randall, C. E., et al. (2002), Validation of POAM III $\mathrm{NO}_{2}$ measurements, J. Geophys. Res., 107(D20), 4432, doi:10.1029/2001JD001520.

Reburn, W. J., J. J. Remedios, P. E. Morris, C. D. Rodgers, F. W. Taylor, B. J. Kerridge, R. J. Knight, J. Ballard, J. B. Kumer, and S. T. Massie (1996), Validation of $\mathrm{NO}_{2}$ measurements from the ISAMS, J. Geophys. Res., 101, 9873-9895.

Renard, J.-B., M. Pirre, C. Robert, G. Moreau, D. Huguenin, and J. M. Russell (1996), Nocturnal vertical distribution of stratospheric $\mathrm{O}_{3}, \mathrm{NO}_{2}$ and $\mathrm{NO}_{3}$ from balloon measurements, J. Geophys. Res., 101, 28,79328,804

Renard, J.-B., F. G. Taupin, E. D. Rivière, M. Pirre, N. Huret, G. Berthet, C. Robert, and M. Chartier (2001), Measurement and simulation of stratospheric $\mathrm{NO}_{3}$ at mid and high latitudes in the Northern Hemisphere, J. Geophys. Res., 106, 32,387-32,399.

Renard, J.-B., et al. (2004), Validation of GOMOS vertical profiles using balloon-borne instruments and satellite data, in Proceedings of the Second Workshop on the Atmospheric Chemistry Validation of ENVISAT (ACVE-2), ESA-ESRIN, Frascati, Italy, 3-7 May 2004, pp. 60.1-60.7, Eur. Space Agency, Noordwijk, Netherlands.
Renard, J.-B., et al. (2005), $\mathrm{NO}_{3}$ vertical profile measurements from remote sensing balloon-borne spectrometers and comparison with model calculations, J. Atmos. Chem., 51, 65-78.

Russell, J., J. Gille, E. Remsberg, L. Gordley, P. Bailey, S. Drayson, H. Fischer, A. Girard, J. Harries, and W. Evans (1988), Validation of nitrogen dioxide results measured by the Limb Infrared Monitor of the Stratosphere (LIMS) experiment on Nimbus 7, J. Geophys. Res., 93, 1718-1736.

Seppälä, A., P. T. Veronen, E. Kyrölä, S. Hassinen, L. Backman, A. Hauchecorne, J.-L. Bertaux, and D. Fussen (2004), Solar proton events of October-November 2003: Ozone depletion in the Northern Hemisphere polar winter as seen by GOMOS/Envisat, Geophys. Res. Lett., 31, L19107, doi:10.1029/2004GL021042.

Sioris, C. E., et al. (2003), Stratospheric profiles of nitrogen dioxide observed by Optical Spectrograph and Infrared Imager System on the Odin satellite, J. Geophys. Res., 108(D7), 4215, doi:10.1029/2002JD002672.

Vandaele, A. C., C. Hermans, S. Fally, M. Carleer, R. Colin, M.-F. Mérienne, A. Jenouvrier, and B. Coquart (2002), High-resolution Fourier transform measurement of the $\mathrm{NO}_{2}$ visible and near-infrared absorption cross sections: Temperature and pressure effects, J. Geophys. Res., 107(D18), 4348, doi:10.1029/2001JD000971.

Verronen, P. T., E. Turunen, T. Ulich, and E. Kyrölä (2002), Modelling the effects of the October 1989 solar proton event on mesospheric odd nitrogen using a detailed ion and neutral chemistry model, Ann. Geohys., 20, $1967-1976$.

Yee, J.-H., et al. (2002), Atmospheric remote sensing using a combined extinctive and refractive stellar occultation technique: 1 . Overview and proof-of-concept observations, J. Geophys. Res., 107(D14), 4213, doi:10.1029/2001JD000794

G. Barrot, O. Fanton d'Andon, M. Guirlet, A. Mangin, and B. Théodore, ACRI-ST, 260 rue du Pin Montard, BP 234, F-06904 Sophia-Antipolis, France.

S. Bekki, J.-L. Bertaux, C. Cot, F. Dalaudier, A. Hauchecorne, J.-C. Lebrun, and M. Marchand, Service d'Aéronomie/Institut Pierre Simon Laplace, Centre National de la Recherche Scientifique, B.P. 3, Reduit de Verrieres, F-91371 Verrières-le-Buisson, France. (alain.hauchecorne@ aerov.jussieu.fr)

R. Fraisse, European Aeronautic Defence and Space-Astrium, F-31400 Toulouse, France.

D. Fussen and F. Vanhellemont, Belgian Institute for Space Aeronomy, 3, avenue Circulaire, B-1180 Brussels, Belgium.

R. Koopman and L. Saavedra de Miguel, European Space Agency/ European Space Research Institute, Via Galileo Galilei, Casella Postale 64, I-00044 Frascati, Italy.

E. Kyrölä, V. Sofieva, and J. Tamminen, Finnish Meteorological Institute, Earth Observation, P.O. Box 503, FIN-00101 Helsinki, Finland.

J.-B. Renard, Laboratoire de Physique et Chimie de l'Environnement, Centre National de la Recherche Scientifique, 3A Avenue de la Recherche Scientifique, F-45071 Orleans, Cedex 2, France.

P. Snoeij, European Space Agency/European Space Research and Technology Centre, Keplerlaan 1, Postbus 299, Noordwijk, 2200 AG, Netherlands. 